\title{
The Impact of Internet Addiction on Life Satisfaction and Life Engagement in Young Adults
}

\author{
Ishrat Shahnaz ${ }^{*}$, A.K.M. Rezaul Karim \\ Department of Psychology, University of Dhaka, 1000 Dhaka, Bangladesh \\ *Corresponding Author: dola_u8@yahoo.com
}

Copyright $@ 2014$ Horizon Research Publishing All rights reserved.

\begin{abstract}
This study examined the impact of Internet addiction (IA) on life satisfaction and life engagement in young adults. A total of 210 University students participated in the study. Multivariate regression analysis showed that the model was significant and contributes $8 \%$ of the variance in life satisfaction (Adjusted $\mathrm{R}^{2}=.080, p<.001$ ) and $2.8 \%$ of the variance in life engagement (Adjusted $\mathrm{R}^{2}=.028, p<.05$ ). Unstandardized regression coefficient $(\mathrm{B})$ indicates that one unit increase in raw score of Internet addiction leads to .168 unit decrease in raw score of life satisfaction $(B=-.168$, $p<.001)$ and .066 unit decrease in raw score of life engagement $(\mathrm{B}=-.066, p<.05)$. Means and standard deviations of the scores on IA and its dimensions showed that the most commonly given purposes of Internet are online discussion, adult chatting, online gaming, chatting, cyber affair and watching pornography. Means and standard deviations of the scores on IA and its dimensions across different types of social networking sites further indicate that people who frequently participate in skype, twitter and facebook have relatively higher IA score. Correlations of different aspects of Internet use with major variables indicate significant and positive correlations of Internet use with IA, neglect of duty and virtual fantasies. Implications of the findings for theory, research and practice are discussed.
\end{abstract}

Keywords Internet Addiction, Life Satisfaction, Life Engagement and Internet Use

\section{Introduction}

As the rapid advancement of the technology and world-wide expansion of web has remarkably improved the people's quality of life by removing all the barriers across the world, the Internet has been considered a blessing for the human society. It has become a constant, important source of information and entertainment among the people. Emails, blogs, social networks, instant messaging and message boards allow for both public and anonymous communication about any topics. Today, as a collection of various services and resources, the Internet has become the most ever powerful tool for human being. Just as a popular saying goes, "Internet has brought a globe in a single room, and even the palm of one's hand" [1]. However, in recent years, the use of Internet has skyrocketed and affected everyone's life, specifically, adolescents and young adults, a generation for whom the line between online and real world interaction is practically non-existent and the existence of addictive Internet use may exert detrimental effects on their lives. The presence of addictive behaviors among some Internet users has drawn the attention of the public and helping professionals since the early 1990s. Research into the potential problems of excessive Internet use has increased substantially over the past two decades.

\subsection{Internet Addiction}

Much dependence on Internet triggered a condition defined as 'Internet addiction disorder' [2,3]. In 1995, Ivan Goldberg borrowed criteria for defining psychoactive substance dependence in the DSM-IV and first coined the term "Internet addiction disorder (IDA)" to represent those having problematic Internet use behavior [4-6]. Similarly, as a leading expert in the field of problematic Internet use behavior, Kimberly Young presented the first empirical research on Internet addiction in 1996 at the American Psychological Association's annual conference in her paper titled "Internet Addiction: The Emergence of a New Disorder. "According to her, Internet addiction (IA) is any online-related, compulsive behaviour which interferes with normal living and causes severe stress on family, friends, loved ones, and one's work environment. Young also developed the 7-item, 8-item, 10-item, and 20-item scales, namely, the Internet Addiction Test, for assessing "Internet dependent" or "Internet addicted" behavior. In one of her early studies with a sample of 596 self-selected Internet users, Young found that $66 \%$ of the respondents could be classified as "Internet dependent," who displayed an array of addictive behaviors including tolerance, loss of control, withdrawal, and impairment of functioning. Among these identified individuals, negative academic, social, financial, and occupational consequences caused by Internet addiction were also observed. Physical problems, social isolation, 
familial, psychological and academic problems have all been identified as a consequence of excessive Internet use [7]. Based on these findings, Young pointed out that Internet addiction adversely affect one's physical health, family life, and academic performance and ought to be designated as a mental disorder. Since then, a lot of research and debates about Internet addiction have been generated. A study with American participants demonstrated that addicts use the Internet an average of 38 hours a week for non-academic and non-employment purposes resulting in poor grades among students, discord among couples and reduced work performance [8]. Another study in Taiwan showed that Internet addictionwas associated with symptoms of attention deficiency and hyper activity disorder (ADHD) and depressive disorders [9]. This phenomenon affects people with varying frequency around the world and has produced negative impacts on the academic, relationship, financial, and occupational aspects of many lives [10,2,11]. So, it is considered a psychological problem worldwide since it has a negative effect on behavior, such as preventing social interactions and reducing academic performance [11-12] impairing personal functions [14] and harming personal relationships [15].

Internet addicts make the Internet a priority more important than family, friends, and work. They stay online for long hours, prefer to contact people with Internet instead of other forms of social contact and want to stay online rather than experiencing life events outside [16]. They are willing to sacrifice what they cherish most in order to preserve and continue their unhealthy behavior [17]. In his studies, Greenfield [18] found that "online addicts feel a sense of displacement when online and are unable to manage central aspects of their lives due to their growing preoccupation with online use. They start to miss important deadlines at work, spend less time with their family, and slowly withdraw from their normal routines. They neglect social connections with their friends, coworkers, and with their communities, and ultimately, their lives become unmanageable because of the Internet. As the addiction grows, they become consumed with their Internet activities, preferring online games, chatting with online friends, or gambling over the Internet, gradually ignoring family and friends in exchange for solitary time in front of the computer." These behaviors could affect the lives of users irreparably if not treated with appropriate methods.

\subsubsection{Theories of Internet Addiction}

To understand how problematic Internet use leads to psychological problems or why people are suffering from psychological disorders develop a tendency for problematic Internet use, some theories on the topic need to be examined. A number of theories have been suggested to explain the reasons for Internet use. Cognitive-behavioural theory [19], the social skill model [20], and social-cognitive theory [21] could be employed. [22]

According to cognitive-behavioural theory, biases in individuals' perceptions and memory processes associated with Internet use are the causes of Internet addiction. It does not define problematic Internet use simply as a behavioural addiction, but also as a cognitive-behavioural condition with serious negative impacts on one's life. Among various cognitive-behavioral models, one leading theory about Internet addiction is the cognitive-behavioral theory of pathological Internet use proposed by Davis [19]. According to Davis [19], people suffering from obsessive thoughts start to accept the Internet as a 'friend,' and this in turn triggers problematic behaviour [23]. Grohol [24] explains Internet addiction using the cognitive-behavioural approach. Rather than examining the nature of the addiction, he focuses on the 'compulsive behaviour' and its 'treatment' [25]. Problematic Internet use is defined as a multidimensional condition leading to negative social, academic and professional outcomes and manifesting cognitive-behavioural symptoms [20].

Behavioral theories state that environmental events determine human behavior through the process of learning (classic conditioning and operant conditioning). According to classical conditioning, it is believed that Internet use behavior may be repeatedly paired up with some emotional experiences and/or environmental cues and thus formulate an association with these factors. As such, while individuals are exposed in similar environment and experiences that are associated with Internet use, they may automatically/unconsciously wish to use the Internet. According to operant conditioning, surfing on the Internet may produce a variety of desirable consequences including approval, relaxed feeling, tension reduction, avoidance of withdrawal symptoms, and disappearance of negative emotions. Under this principle, all these desirable consequences may positively reinforce the Internet use behavior and eventually lead to Internet addiction $[26,27,1]$.

\subsection{Life Satisfaction}

Life satisfaction is one of the several aspects of positive mental health. It refers to a cognitive, judgmental process. It is not a direct, verifiable experience, nor a known personal fact, but a cognitive product that involves a comparative process between the individual's current life situation and internalized standards, allowing respondents to use the information they subjectively deem relevant when evaluating their own lives [28]. It is the way a person perceives how his or her life has been and how they feel about where it is going in the future. Shin and Johnson [29] define life satisfaction as "a global assessment of a person's quality of life according to his chosen criteria". Judgments of satisfaction are dependent upon a comparison of one's circumstances with what is thought to be an appropriate standard. It is important to point out that the judgment of how satisfied people are with their present state of affairs is based on a comparison with a standard which each individual sets for him or herself; it is not externally imposed.

Life satisfaction is an overall assessment of feelings and attitudes about one's life at a particular point in time ranging 
from negative to positive. It is one of the major indicators of subjective well-being [30]. Subjective well-being represents a hedonic well-being concept with roots in the mid-seventies when Andrews and Whitey [31] introduced a well-being structure consisting of three factors: cognitive evaluation, negative affect, and positive affect. Some years later Diener [30] rephrased the concept using the narrower name subjective well-being, with the intention of accentuating the importance of assessing the subjective experience of life in contrast to an assessment of life conditions using an absolute, fixed standard as a reference. According to him, subjective well-being covers two main components: one affective including negative and positive emotions, and one cognitive; namely life satisfaction (Figure 1).

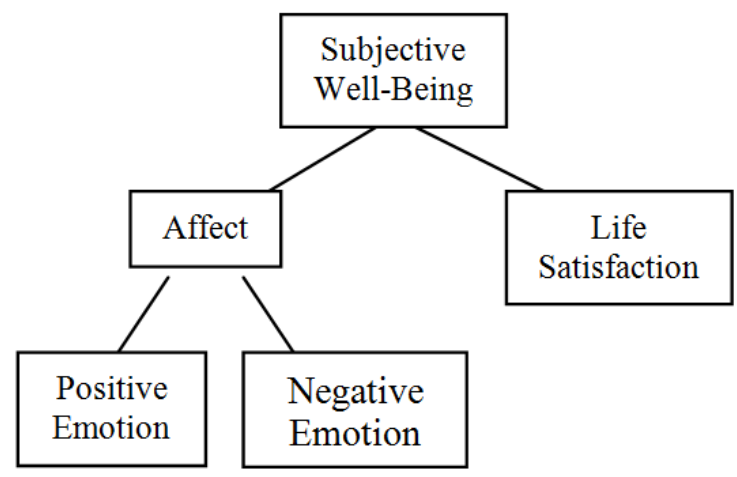

Figure 1. The Concept of Life Satisfaction in a Subjective Well-Being Framework (Source: Diener, 1984).

Diener [30] also explained that subjective and objective perspectives are used to explain the determinants of life satisfaction or quality of life. The subjective construct hypothesizes that perceived quality of life is influenced by personality or dispositional factors (e.g., optimism, pessimism, isolation, self-worth, and neuroticism). On the other hand, the objective construct proposes that life quality is affected by environmental or situational factors (e.g., family, job, leisure, neighborhood, community, and satisfaction with standard of living) [32]. According to the objective determinants of life quality, people's quality of life tends to be a direct function of their evaluations of important life domains such as social support, leisure activities, and standard of living of overall life [30,31].

Life satisfaction can also be looked at in a new one as influenced by a family. Family life satisfaction is a pertinent topic as everyone's family influences them in some way and most strive to have high levels of satisfaction in life as well as within their own family. Greater life satisfaction within a family increases through communication and understanding each member's attitudes and perceptions. People who personally valued material items were found to be less satisfied overall in life as opposed to people who attached a higher amount of value with interpersonal relationships. But people are becoming isolated from their families as they are spending much time in Internet. Loneliness is the most important variable associated with Internet addiction and its dimensions [33]. Pratarelli, Brown and Johnson [34] argued that increased Internet use was associated with feelings of isolation, which were mutually reinforcing. A study on the USA children revealed that children using the Internet have a very limited dimension of friendship [35]. They also spend less time talking with their families, experiencing more daily stress, and feeling lonelier and depressed [35]. Regarding the impact on psychosocial well-being, Internet addiction was found to be associated with subjective distress and social impairment in Hong Kong [36]. Weiser [37] found a negative association between daily Internet use and general wellbeing when the participants' Internet use had a "social orientation'. In contrast, however, several studies found no relationship between daily Internet use and well-being [38-40].

\subsection{Life Engagement}

Life engagement which is another focus of the present study refers to the purpose in life. It also refers to the engagement in behavior that sustains life [41]. It is defined in terms of the extent to which a person engages in activities that are valued [42]. Given the central role that behavior plays in living, it is important to ask why people act. What is it that causes people to behave and remain engaged in what they do?

Recent models of behavioral self-regulation [41-43], themselves descendents of generations of expectancy value models of motivation [45-48] suggest that two elements are important in creating behavior: (a) the ability to identify goals that are valued and (b) the perception that those goals are attainable. Of these two elements, it is the value dimension that is of interest here. Valued goals are important because they provide a purpose for living. Valued goals also provide the mechanism by which a person remains behaviorally engaged in life. According to this view, behavior occurs either because the behavior represents a valued goal in and of itself (e.g., exercising for exercise sake) or because it is instrumental in achieving a more abstract, higher order goal that is valued (e.g., exercising in order to be "healthy").

Contrary to a plethora of studies that examined the relationship between Internet addiction and life satisfaction, only few studies explored the relationship between Internet addiction and life engagement. There are some research findings showing that adolescents experience the negative impact of Internet addictive behaviors. For example, in a study on 1,716 students of grade I to grade III in Hong Kong, 'Against Child Abuse' found that $37 \%$ of the respondents admitted that they "could not resist the attraction from being on-line" and $28.5 \%$ of the respondents agreed that "on-line activities largely affected their normal daily lives [49]. Choi, $\mathrm{Wu}, \mathrm{Zah}$ and Ying [50] also found that in Hong Kong 17.1\% of the adolescent respondents who spent more than 6 hour on-line daily had difficulty in controlling their unstable emotions. 
Life satisfaction can reflect experiences that have affected a person in a positive way. These experiences have the ability to motivate people to pursue and reach their goals. Positive views and life satisfaction are completely mediated by the concept of self-esteem, and the different way ideas and events are perceived by people. One's mood and outlook on life can also influence one's own perception of their life satisfaction. Satisfaction or dissatisfaction with standard of living is likely to spill over to influence subjective well-being [32] and this quality of life can be associated with life engagement which is also an important aspect of mental health. A study in USA showed that life engagement was a significant predictor of elders' life satisfaction [51]. And these both components can be affected by overuse of Internet.

\subsection{The Present Study}

The review of literature as above shows that Internet addiction has strong correlation with life satisfaction. These findings give some understanding of how Internet addiction is associated with the addicts' life satisfaction but the direct associations of Internet addiction with life satisfaction is still inconclusive (e. g., some studies found relationship whereas some found no relationship between Internet addiction and life satisfaction). Moreover, it is yet to investigate how Internet addiction is associated with life engagement, a variable assumed to be associated with life satisfaction. What scientists have known till today about the impact of Internet addiction on human life reflect the story of the Western or advanced cultures and societies. Data are not available from a collectivistic or conservative society like Bangladesh. In Bangladesh the first connectivity of Internet became a reality in 1996 [52]. The number of Internet users in the country grew from 92,061 in 2000 to $2,591,223$ in 2007 , to $4,557,935$ in 2009 to $30,390,374$ in 2013and to 40,832,387 in 2014 [53]. According to latest reports of Bangladesh Telecommunication Regulatory Commission [54], there are about 39,328,613 mobile Internet users, 1,231,940 ISP (Internet Service Provider) plus PSTN (Public circuit-Switched Telephone Networks) users and 271,831 WiMAX (Worldwide Interoperability for Microwave Access) users in Bangladesh. This development of Internet service has touched people's life more or less almost at every nook and corner in the country. However, studies on Internet addiction is rarely done in our country. One exception is a scale validation study conducted by Karim \& Nigar [52].

It is, therefore, essential to conduct a study to focus on Internet addiction and its impacts on the users, especially on college/university students. For this reason, we selected university students of our country. Among the people threatened with the excessive Internet use, university students are considered as a potential group for investigating IA[55]. Free and unlimited Internet access, long periods of unstructured time, newly experienced freedom from parental control, no monitoring or censoring of what they say or do online, full encouragement from faculty and administrators, social intimidation and alienation, are all possible reasons for IA among university students [56]. In Turkey, people between 24 to 34 years of age and who attend higher education have been using Internet more than other groups [57]. A survey of university freshmen in China showed that a single-parent family, the age of first exposure to Internet use, the age of the student, city residence, and homesickness were significantly associated with Internet addiction [58].

In view of the age range of this group, we can assume that Internet addiction can be a serious risk for university students in our country and it can hamper their life satisfaction and life engagement. Thus the present study was designed to answer the questions: (a) does Internet addiction affect life satisfaction of Internet addicts? and (b) does Internet addiction disturb their life engagement? Based on the past findings $[30,35,36,59]$, we hypothesized that Internet addiction would have negative impact on life satisfaction and life engagement.

\section{Materials and Methods}

\subsection{Participants}

A total of 210 undergraduate and graduate students studying in the University of Dhaka voluntarily participated in the study. Among the participants 117 (55.7\%) were females and $93(44.3 \%)$ were males. Their age ranged from 22 to 25 years with a mean of 23.38 and standard deviation of $.97 .11 \%$ of the participants were from lower class family, $70.5 \%$ were from middle class family and $18.5 \%$ were from upper class family.3.23\% of the male participants and $14.53 \%$ of the female participants were married, whereas $29.03 \%$ of the male participants and $39.32 \%$ of the female participants were in a relationship. All the participants had Internet connection to their personal computers and/or to their mobile phones.

\subsection{Measures}

\subsubsection{Survey of Internet Use}

Participants filled out a questionnaire including items about how long they are using Internet, how many times they use Internet per day, how long they spent on the Internet per day, what kind of activities they perform and what kind of sites they use on the Internet. The duration of Internet use ranged from 5 months to 12 years with a mean of 3.65 years. The frequency of Internet usage ranged from 1 to 16 times a day. Time spent online per day ranged from 15 minutes to 12 hours, with a mean of 2.29 hours. Of the participants, $92.9 \%$ used facebook, $10 \%$ used twitter, $45.7 \%$ used yahoo messenger, $15.3 \%$ used google talk, $34.3 \%$ used skype and $3.3 \%$ used other sites. Among them, 78.1\% used Internet for email, $82.9 \%$ for search, $81.4 \%$ for download, 21.9 for online game, $64.8 \%$ for chat, $6.7 \%$ for online discussion, $1.4 \%$ for cyber affair, $10.5 \%$ for adult chat, $18.6 \%$ for pornography, and $9.5 \%$ for other activities. 
Table 1. Cutoff scores for categorizing Internet users on the IAT

\begin{tabular}{cccc}
\hline & $\begin{array}{c}5 \text { point response } \\
\text { format }\end{array}$ & $\begin{array}{c}5 \text { point response } \\
\text { format }\end{array}$ & 6 point response format \\
\hline User category & $\begin{array}{c}20 \text {-item English } \\
\text { IAT }^{\text {ab }}\end{array}$ & $\begin{array}{c}\text { 18-item Bangla } \\
\text { IAT }^{\mathrm{C}}\end{array}$ & 18-item Bangla IAT \\
\hline Minimal users & $20-39$ & $18-35$ & $18-44$ \\
Moderate users & $40-69$ & $36-62$ & $45-71$ \\
Excessive users & $70-100$ & $63-90$ & $72-90$ \\
\hline
\end{tabular}

Minimal users: Lower score $=$ Number of items $\times 1.0$, Upper score $=$ Number of items $\times 2.5-1.0$.

Moderate users: Lower score $=$ Number of items $x 2.5$, Upper score $=$ Number of items $\times$ 4.0-1.0.

Excessive users: Lower score $=$ Number of items $\times 4.0$, Upper score $=$ Number of items $\times 5.0$.

a [60]

$\mathrm{b}[61]$

c [52]

\subsubsection{Internet Addiction Test}

The Bangla version of the Internet Addiction Test (IAT) [52] was used to assess the addiction level of the participants. The original IAT, developed by Young [7], is the first validated and reliable measure of addictive use of the Internet. It is a 20-item questionnaire that measures psychological dependence, compulsive use, and withdrawal as well as related problems of education, sleep, family and time management. The Bangla version instrument comprises 18 items. Each of the items is rated on a 5-point response format ranging from 1 (rarely) to 5 (always). The minimum obtainable score on the Bangla version IAT is 18 and the maximum is 90 . The higher the score the greater is the level of Internet addiction. Based on the severity of addictive behavior, individuals on the IAT can be classified as minimal users (18-35), moderate users (36-62) or excessive users (63-90) [52]. However, we used in this study a 6-point response format ranging from 0 (does not apply) to 5 (always) [11]. If this response format is used with the 18-item Bangla version IAT, the minimal users' score fall in the range of $18-44$, the moderate users' scores fall in the range of 45-71 and the excessive users' scores fall in the range of 72-90 (Table 1). Minimal users are the average online users who have complete control over their Internet usage. Moderate users are those experiencing occasional or frequent problems due to Internet usage. Excessive users are those having significant problems caused by Internet usage.

The internal consistency (Cronbach's $\alpha$ ) of the original IAT was 0.92 , the test-retest reliability being satisfactory with high face validity. The average inter-item correlation for the Bangla version IAT was .29 and the standardized Cronbach's $\alpha$ coefficient was .89. The correlation between IAT and MSIS was significant $(r=-.25)$, supporting the discriminant validity of the measures [52].

\subsubsection{Satisfaction With Life Scale}

The Bangla version of the Satisfaction With Life Scale (SWLS) [62] was used to measure global cognitive judgments of participant's life satisfaction. A 5-item SWLS, originally developed by Diener, Emmons, Larsen and Griffin [63], is a 7-point Likert type scale ranging from 1 (strongly disagree) to 7 (strongly agree). Individuals on the SWLS can be classified as extremely dissatisfied ( $5-9)$, dissatisfied (10 - 14), slightly dissatisfied (15 - 19), neutral (20), slightly satisfied $(21-25)$, satisfied $(26-30)$, and extremely satisfied $(31-35)$. The average inter-item correlation coefficient for the Bangla version of SWLS was .44 and cronbach's $\alpha$ (standardized) was .79. The correlation between the SWLS and IAT was significant $(r=-.29)$ supporting the discriminant validity of the measures. The scale also showed adequate convergent validity $(r=.44)$ in relation to the Life Engagement Test [62].

\subsubsection{Life Engagement Test}

The Bangla version of the Life Engagement Test (LET) [62] was designed to measure purpose in life. The 6-item LET, originally developed by Scheier et al. [42], is a 5-point Likert type scale ranging from 1 (strongly disagree) to 5 (strongly agree). Higher scores indicate more life engagement. The average inter-item correlation coefficient for the Bangla version LET was .35 and cronbach's $\alpha$ (standardized) was .77. The correlation between the LET and IAT was significant $(r=-.18)$ supporting the discriminant validity of the measures. As mentioned above this scale has also strong convergent validity.

\subsection{Procedure}

The students participated in the study on a voluntary basis. Each participant was briefed about the general study purpose and assured that their responses would be kept confidential and used only for research purposes. The survey components included an informed consent statement, socio- demographic section, the IAT, the SWLS and the LET. Participants were given a general instruction verbally and were asked to sign on the consent paper, record the socio-demographic information, and read carefully the standard instructions of how to respond before going through the items or questions of the test/scale. Further clarifications were also done whenever they faced any problems to understand the items. Before answering any questions they were asked to provide general demographic data (age, gender, marital status, relationship status, SES etc.). As mentioned before the survey further collected information about different aspects of Inter use. Thus the surveys were administered and data 
were collected over an 8-week period from all the participants.

\subsection{Data Analysis}

Each participant's responses to the scale/test items were scored according to the scoring principles of the IAT, the SWLS and the LET. Before the main analyses, a preliminary analysis was done in MANOVA to see the impacts of subject's characteristics (gender, marital status, relationship status and SES) on life satisfaction and life engagement. Finally, to examine the impact of Internet addiction on life satisfaction and life engagement, the obtained data were analyzed in multivariate regression (the relevant assumptions were tested and found to be satisfied) using Internet addiction as a predictor and life satisfaction and life engagement as the criterion variables.

\section{Results}

\subsection{Preliminary Analysis}

Before collapsing data across gender, marital status, relationship status and SES, one MANOVA was conducted using these socio-demographic variables as independent variables and the major variables (i.e., life satisfaction and life engagement) as dependent variables. No significant multivariate effect was detected for gender $(\mathrm{F}(2,193)=.086$, $\mathrm{p}=.917)$, marital status $(\mathrm{F}(2,193)=.199, \mathrm{p}=.820)$, relationship status $(\mathrm{F}(2,193)=.364, \mathrm{p}=.695)$ and SES $(\mathrm{F}$ $(4,388)=.978, p=.420)$. On the basis of these findings, we decided to collapse the data across gender, marital status, relationship status and SES.

\subsection{Main Analysis}

To examine the impact of Internet addiction on life satisfaction and life engagement, data were analyzed in multivariateregression using Internet addiction as the predictor variable and life satisfaction and life engagement as the criterion variables (Table 2). The multivariate test result shows that the Pillai's Trace (.088) was statistically significant $\left(\mathrm{F}_{2,207}=9.959, \mathrm{p}<.001\right)$. The univariate test result shows that the overall model is significant with both life satisfaction $(\mathrm{F}=19.142, \mathrm{p}=.001)$ and life engagement $(\mathrm{F}=7.123, \mathrm{p}<.05)$.

Parameter estimates in Table 3 indicate that the respondents' Internet addiction was significantly and negatively associated with life satisfaction $(\mathrm{p}<.001)$ and life engagement $(\mathrm{p}<.05)$. Adjusted $\mathrm{R}^{2}$ indicates that the model was significant and explains $8 \%$ of the variance in life satisfaction $(p<.001)$ and $2.8 \%$ of the variance in life engagement $(\mathrm{p}<.05)$.

The unstandardized regression coefficient, B (standardized coefficients cannot be produced in multivariate regression analysis), for Internet addiction indicate that one unit increase in raw score of Internet addiction leads to .168 unit decrease in raw score of life satisfaction and .066 unit decrease in raw score of life engagement. Thus the results indicate that life satisfaction and life engagement can be predicted by Internet addiction.

Table 2. Multivariate and Univariate Test Results for the model

\begin{tabular}{|c|c|c|c|}
\hline \multirow{2}{*}{ Predictor } & \multirow{2}{*}{$\begin{array}{l}\text { Criterion } \\
\text { variables }\end{array}$} & \multicolumn{2}{|c|}{ Statistical tests } \\
\hline & & Pillai's Trace $(F)$ & Univariate $(\mathrm{F})$ \\
\hline \multirow[t]{3}{*}{ Internet addiction } & & $9.959^{\mathrm{a}^{* *}}$ & \\
\hline & Life satisfaction & & $19.142^{* *}$ \\
\hline & Life engagement & & $7.123^{*}$ \\
\hline
\end{tabular}

Table 3. Parameter estimates

\begin{tabular}{|c|c|c|c|c|}
\hline Dependent Variable & Parameter & $\begin{array}{c}\text { B } \\
\text { (Unstandardized) }\end{array}$ & Std. Error & $\mathrm{t}$ \\
\hline \multirow{2}{*}{ Life satisfaction ${ }^{a}$} & Intercept & 25.128 & .786 & $32.055 * *$ \\
\hline & Internet addiction & -.168 & .038 & $-4.375 * *$ \\
\hline \multirow{2}{*}{ Life engagement ${ }^{b}$} & Intercept & 25.134 & .507 & $49.547 * *$ \\
\hline & Internet addiction & -.066 & .025 & $-2.669 *$ \\
\hline
\end{tabular}

Note: $* * \mathrm{p}<.001, * \mathrm{p}<.05$

a. Adjusted R Squared $=.080 \quad$ b. Adjusted R Squared $=.028$ 


\subsection{Means and Standard Deviations of the Scores on Internet Addiction and Dimensions of Internet Addiction across the Purposes of Internet Use}

When the means of the scores on Internet addiction and dimensions of Internet addiction (neglect of duty, online dependency, virtual fantasies and privacy and self-defense) were computed across the purposes of Internet use (Table 4), the results showed wide variation. The mean 'Internet addiction' score was highest for online discussion ( $\mathrm{M}=27.29$, $\mathrm{SD}=12.95)$ followed by the means for adult chatting $(\mathrm{M}=21.64, \mathrm{SD}=15.13)$, online gaming $(\mathrm{M}=19.39, \mathrm{SD}=11.82)$, cyber affair $(M=19.33, \mathrm{SD}=16.44)$, watching pornography $(\mathrm{M}=18.64, \quad \mathrm{SD}=12.80)$, chatting $(\mathrm{M}=18.43, \mathrm{SD}=12.19)$, emailing $(\mathrm{M}=17.71, \mathrm{SD}=12.56)$, downloading $(\mathrm{M}=17.38$, $\mathrm{SD}=12.21)$ and searching $(\mathrm{M}=16.48, \mathrm{SD}=12.48)$. The mean 'neglect of duty' score was highest for online discussion $(\mathrm{M}=10.71, \mathrm{SD}=6.18)$ followed by the means for adult chatting $(\mathrm{M}=8.05, \quad \mathrm{SD}=6.73)$, cyber affair $(\mathrm{M}=7.67$, $\mathrm{SD}=3.05)$, online gaming $(\mathrm{M}=7.59, \mathrm{SD}=5.05)$, watching pornography $(\mathrm{M}=7.26, \quad \mathrm{SD}=5.10), \quad$ chatting $(\mathrm{M}=6.65$, $\mathrm{SD}=4.96)$, emailing $(\mathrm{M}=6.57, \mathrm{SD}=4.92)$, downloading $(\mathrm{M}=6.47, \mathrm{SD}=4.80)$ and searching $(\mathrm{M}=6.07, \mathrm{SD}=4.89)$. The mean 'online dependency' score was highest for online discussion $(\mathrm{M}=4.36, \mathrm{SD}=2.34)$ followed by the means for adult chatting $(\mathrm{M}=3.50, \mathrm{SD}=3.41)$, watching pornography $(\mathrm{M}=3.05, \mathrm{SD}=3.62)$, chatting $(\mathrm{M}=3.03, \mathrm{SD}=3.24)$, emailing $(\mathrm{M}=2.74, \quad \mathrm{SD}=3.29)$, downloading $(\mathrm{M}=2.70, \mathrm{SD}=3.24)$, cyber affair $(\mathrm{M}=2.67, \mathrm{SD}=3.79)$, online gaming $(\mathrm{M}=2.59$, $\mathrm{SD}=2.95)$ and searching $(\mathrm{M}=2.58, \mathrm{SD}=3.19)$. The mean 'virtual fantasies' score was highest for online discussion $(\mathrm{M}=7.29, \mathrm{SD}=3.97)$ followed by the means for cyber affair $(\mathrm{M}=6.00, \mathrm{SD}=7.00)$, online gaming $(\mathrm{M}=5.74, \mathrm{SD}=3.54)$, adult chatting $(\mathrm{M}=5.59, \mathrm{SD}=4.40)$, chatting $(\mathrm{M}=5.30$, $\mathrm{SD}=3.80)$, emailing $(\mathrm{M}=5.16, \quad \mathrm{SD}=3.92)$, downloading $(\mathrm{M}=5.01, \quad \mathrm{SD}=3.86)$ watching pornography $(\mathrm{M}=4.87$,
$\mathrm{SD}=3.44)$ and searching $(\mathrm{M}=4.70, \mathrm{SD}=3.92)$. The mean 'privacy and self-defense' score was highest for online discussion $(\mathrm{M}=4.93, \mathrm{SD}=3.36)$ followed by the means for adult chatting $(\mathrm{M}=4.50, \mathrm{SD}=3.20)$, online gaming $(\mathrm{M}=3.49$, $\mathrm{SD}=2.96)$, watching pornography $(\mathrm{M}=3.46, \mathrm{SD}=2.79)$, chatting $(\mathrm{M}=3.45, \mathrm{SD}=2.74)$, emailing $(\mathrm{M}=3.24, \mathrm{SD}=2.81)$, downloading $(\mathrm{M}=3.20, \mathrm{SD}=2.73)$, searching $(\mathrm{M}=3.12$, $\mathrm{SD}=2.81)$ and cyber affair $(\mathrm{M}=3.00, \mathrm{SD}=2.65)$.

\subsection{Means and Standard Deviations of the Scores on Internet Addiction and Dimensions of Internet Addiction across Different Types of Social Networking Sites.}

When the means of Internet addiction and Internet addiction dimensions were computed across different types of social networking sites (Table 5), the results showed that the mean 'Internet addiction' score, the mean 'neglect of duty' score and the mean 'virtual fantasies' score were highest for skype $(\mathrm{M}=21.57, \mathrm{SD}=14.21 ; \mathrm{M}=7.89, \mathrm{SD}=5.41$; $\mathrm{M}=6.08, \mathrm{SD}=4.40$ ) followed by the means for twitter $(\mathrm{M}=21.19, \quad \mathrm{SD}=10.50 ; \quad \mathrm{M}=7.62, \quad \mathrm{SD}=3.97 ; \quad \mathrm{M}=5.81$, $\mathrm{SD}=3.64)$, facebook $(\mathrm{M}=17.06, \quad \mathrm{SD}=12.15 ; \quad \mathrm{M}=6.20$, $\mathrm{SD}=4.75 ; \mathrm{M}=4.98, \mathrm{SD}=3.85)$, yahoo messenger $(\mathrm{M}=16.39$, $\mathrm{SD}=11.99 ; \mathrm{M}=5.95, \mathrm{SD}=4.65 ; \mathrm{M}=4.52, \mathrm{SD}=3.73)$ and google talk $(\mathrm{M}=14.79, \mathrm{SD}=11.32 ; \mathrm{M}=5.33, \mathrm{SD}=4.39$; $\mathrm{M}=4.09, \mathrm{SD}=3.83$ ). The mean 'online dependency' score was highest for skype $(\mathrm{M}=3.67, \mathrm{SD}=3.68)$ followed by the means for twitter $(\mathrm{M}=3.33, \mathrm{SD}=2.22)$, facebook $(\mathrm{M}=2.73$, $\mathrm{SD}=3.21)$, yahoo messenger $(\mathrm{M}=2.72, \mathrm{SD}=3.16)$ and google talk $(\mathrm{M}=2.18, \mathrm{SD}=2.79)$. The mean 'privacy and self-defense' score was highest for twitter $(\mathrm{M}=4.43, \mathrm{SD}=3.41)$ followed by the means for skype $(\mathrm{M}=3.93, \mathrm{SD}=3.15)$, yahoo messenger $(\mathrm{M}=3.20, \mathrm{SD}=2.76)$, google talk $(\mathrm{M}=3.18$, $\mathrm{SD}=2.65)$ and facebook $(\mathrm{M}=3.14, \mathrm{SD}=2.75)$.

Table 4. Means and standard deviations of the scores on Internet addiction and Internet addiction dimensions across the purposes of Internet use

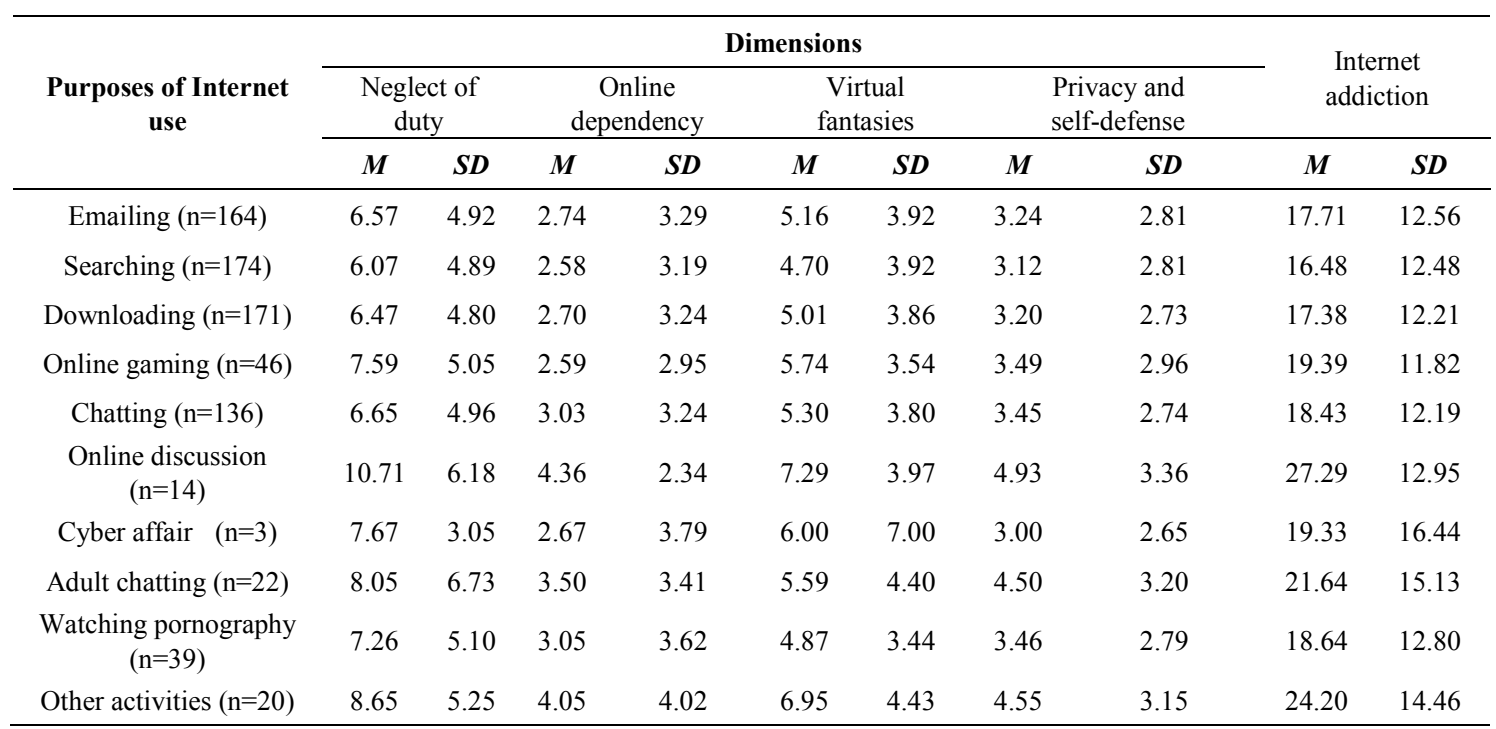


Table 5. Means and standard deviations of Internet addiction and Internet addiction dimensions across different types of social networking sites

\begin{tabular}{|c|c|c|c|c|c|c|c|c|c|c|}
\hline \multirow{3}{*}{$\begin{array}{l}\text { Social networking } \\
\text { sites }\end{array}$} & \multicolumn{8}{|c|}{ Dimensions } & \multirow{2}{*}{\multicolumn{2}{|c|}{ Internet addiction }} \\
\hline & \multicolumn{2}{|c|}{ Neglect of duty } & \multicolumn{2}{|c|}{$\begin{array}{c}\text { Online } \\
\text { dependency }\end{array}$} & \multicolumn{2}{|c|}{ Virtual fantasies } & \multicolumn{2}{|c|}{$\begin{array}{c}\text { Privacy and } \\
\text { self-defense }\end{array}$} & & \\
\hline & $M$ & $S D$ & $M$ & $S D$ & $M$ & $S D$ & $M$ & $S D$ & $M$ & $S D$ \\
\hline Facebook $(n=195)$ & 6.20 & 4.75 & 2.73 & 3.21 & 4.98 & 3.85 & 3.14 & 2.75 & 17.06 & 12.15 \\
\hline Twitter $(\mathrm{n}=21)$ & 7.62 & 3.97 & 3.33 & 2.22 & 5.81 & 3.64 & 4.43 & 3.41 & 21.19 & 10.50 \\
\hline $\begin{array}{l}\text { Yahoo messenger } \\
\quad(\mathrm{n}=96)\end{array}$ & 5.95 & 4.65 & 2.72 & 3.16 & 4.52 & 3.73 & 3.20 & 2.76 & 16.39 & 11.99 \\
\hline Google talk $(n=33)$ & 5.33 & 4.39 & 2.18 & 2.79 & 4.09 & 3.83 & 3.18 & 2.65 & 14.79 & 11.32 \\
\hline Skype $(n=72)$ & 7.89 & 5.41 & 3.67 & 3.68 & 6.08 & 4.40 & 3.93 & 3.15 & 21.57 & 14.21 \\
\hline Other sites $(\mathrm{n}=7)$ & 6.86 & 2.34 & 3.57 & 2.99 & 5.29 & 2.43 & 5.14 & 2.97 & 20.86 & 8.63 \\
\hline
\end{tabular}

Table 6. Correlations of different aspects of Internet use (duration of use, frequency of use, time spent per day) with Internet addiction, dimensions of Internet addiction, life satisfaction and life engagement.

\begin{tabular}{|c|c|c|c|c|}
\hline & & \multicolumn{3}{|c|}{ Internet use } \\
\hline & & Duration of use (years) & $\begin{array}{l}\text { Frequency of use (per } \\
\text { day) }\end{array}$ & $\begin{array}{c}\text { Time spent online } \\
\text { (per day) }\end{array}$ \\
\hline \multicolumn{2}{|c|}{ Internet addiction } & $.25^{* *}$ & $.25^{* *}$ & $.26^{* *}$ \\
\hline \multirow{4}{*}{$\begin{array}{c}\text { Dimensions of } \\
\text { Internet } \\
\text { Addiction }\end{array}$} & Neglect of duty & $.23 * *$ & $.29 * *$ & $.31 * *$ \\
\hline & $\begin{array}{c}\text { Online } \\
\text { dependency }\end{array}$ & $.18^{* *}$ & .12 & .12 \\
\hline & Virtual fantasies & $.26^{* *}$ & $.23 * *$ & $.21 * *$ \\
\hline & $\begin{array}{c}\text { Privacy and self } \\
\text { defense }\end{array}$ & .13 & $.14 *$ & $.19^{* *}$ \\
\hline \multicolumn{2}{|c|}{ Life satisfaction } & -.04 & -.09 & -.08 \\
\hline \multicolumn{2}{|c|}{ Life engagement } & .02 & .05 & .09 \\
\hline
\end{tabular}

Note: $\mathrm{N}=210,{ }^{* *} \mathrm{p}<.01(2$-tailed $),{ }^{*} \mathrm{p}<.05$ (2-tailed)

\subsection{Correlations of Different Aspects of Internet Use (Duration of Use, Frequency of Use, Time Spent Per Day) with Internet Addiction, Dimensions of Internet Addiction, Life Satisfaction and Life Engagement}

In order to examine the relationship of different aspects of Internet use (duration of use, frequency of use, time spent per day) with Internet addiction, dimensions of Internet addiction, life satisfaction and life engagement, Pearson's product moment correlations were calculated (Table 6). Internet addiction was found to correlate significantly with duration of use $(\mathrm{r}=.25, \mathrm{p}<.01)$, frequency of use $(\mathrm{r}=.25, \mathrm{p}<.01)$ and time spent online per day $(\mathrm{r}=.26, \mathrm{p}<.01)$. Neglect of duty was found to correlate significantly with duration of use $(\mathrm{r}=.23, \mathrm{p}<.01)$, frequency of use $(\mathrm{r}=.29, \mathrm{p}<.01)$ and time spent online per day $(\mathrm{r}=.31, \mathrm{p}<.01)$. Online dependency was significantly correlated only with duration of use $(r=.18$, $\mathrm{p}<.01)$. Virtual fantasies was also found to correlate significantly with duration of use $(\mathrm{r}=.26, \mathrm{p}<.01)$, frequency of use $(\mathrm{r}=.23, \mathrm{p}<.01)$ and time spent online per day $(\mathrm{r}=.21$, $\mathrm{p}<.01$ ). Privacy and self-defense was found to correlate significantly with frequency of use $(\mathrm{r}=.14, \mathrm{p}<.05)$ and time spent online per day $(\mathrm{r}=.19, \mathrm{p}<.01)$. However, no significant correlations were found between Internet use (duration of use, frequency of use, time spent per day) and life satisfaction, and between Internet use (duration of use, frequency of use, time spent per day) and life engagement.

\section{Discussion}

Although Internet has been considered a boon for people's life, addiction to it adversely affects their physical health, family life, academic performance, quality of life as well as mental health. The present study was designed to investigate the impact of Internet addiction on life satisfaction and life engagement in young adults. Reviewing the relevant literature, it was hypothesized that Internet addiction would have negative impact on life satisfaction and life engagement. To test these hypotheses data were collected from 210 undergraduate and graduate students of the University of Dhaka. Following standardized procedure the Bangla version IAT, SWLS and LET measures were administered to them. Data for participants' life satisfaction and life engagement were analyzed in multivariate regression using Internet addiction as the predictor. Results support the study hypotheses.

Results obtained in multivariate regression analysis (Table 2) show that the multivariate test result for overall model was significant. The univariate test result shows that the overall model was also significant with both life satisfaction $(\mathrm{F}=19.142, \mathrm{p}=.001)$ and life engagement $(\mathrm{F}=7.123, \mathrm{p}<.05)$. As demonstrated in Table 3, Internet addiction has 
significant and negative impact on both life satisfaction $(\mathrm{B}=$ $-.168, \mathrm{p}<.001)$ and life engagement $(\mathrm{B}=-.066, \mathrm{p}<.05)$. This result supports the hypotheses formulated earlier. People who are satisfied with their life are able to make them engaged to identify the purposes of life. If their satisfaction level is hampered by the addiction to Internet, it is difficult for them to engage in activities that sustain their life and make it purposeful. So, the assumption that Internet addicts would have poor life satisfaction, which, in turn, would lead to decreased life engagement, is supported by the present findings. This might happen because the use of Internet has significantly affected everyone's life, specifically adolescents and young adults, a generation who has forgotten the line between online and real world interaction. The existence of addictive Internet use may exert detrimental effects on their lives. University students, the participants of this study, are part of the young group and are considered as vulnerable to Internet addiction [55]. In comparison to other age groups, Kandell [5] and Nalwa and Anand [64] also found that Internet addiction is a bigger problem among university students. Being away from home, using spare time badly, always available, fast and free Internet and use of the Internet for educational reasons are listed as some of the reasons for increased risk for addiction for this group. As a result, they suffer from physical problems, social isolation, familial, psychological problems (depression, ADHD) and academic problems which have all been identified as a consequence of Internet addiction [7]. All these things impair people's cognitive judgment of satisfaction because people's quality of life tends to be a direct function of their evaluations of important life domains such as social support, leisure activities, and standard of living of overall life $[30,31]$. And being online for long time destructs people to focus on valued goals of their life. Thus their life satisfaction level becomes poor and they find difficulty to be engaged in life. This finding is also supported by other research findings $[65,66,12]$.

This study demonstrated some additional and interesting aspects of Internet addiction. Means and standard deviations of the scores on Internet addiction and its dimensions (Table 4) indicate that the degree of Internet addiction varies across the purposes of Internet use. The most commonly given purposes of Internet use associated with the scores on Internet addiction and its dimensions in the present study were online discussion, adult chatting, online gaming, chatting, cyber affair and watching pornography and the least given purposes were searching, downloading and emailing. That is, people who frequently participate in online discussion, adult chatting, online gaming, chatting, cyber affair and watching pornography have relatively higher Internet addiction score. Many researchers have shown that people might not be addicted to the Internet itself but to particular Internet activities. They claimed that the more interactive an Internet function was, the more addictive it would be to the users [7,23,67-69]. This is consistent with our findings because online discussion, adult chatting, online gaming, chatting, cyber affair and watching pornography are more interactive than searching, downloading and emailing.

Means and standard deviations of the scores on Internet addiction and its dimensions across different types of social networking sites (Table 5) further indicate that people who frequently participate in skype, twitter and facebook have relatively higher Internet addiction score. As the technological advancement of Internet has made significant changes in how people live, behave and interact, people prefer to get their daily share of news/information by looking at stories and updates posted by friends or colleagues and relatives on different social media (e.g., Skype, Twitter and Facebook). By using these sites people can instantly share their feelings, thoughts, ideas, interests, documents and even photos/pictures with other people who are far away geographically. People addicted to these activities and sites display more neglect of duty, dependence online and lives in virtual world more than real world. These findings are supported by other studies [70,71].

Another interesting finding of the study is that correlations of the different aspects of Internet use (duration of use, frequency of use, time spent online per day) suggest significant and positive correlations of duration of Internet use, frequency of use, time spent online per day with Internet addiction, neglect of duty and virtual fantasies (Table 6). It indicates that long term users and those who frequently use Internet and spend lots of time online neglect their duty, social lives and fantasize their cyber world more than others. Duration of Internet use was found to correlate positively with online dependency indicating that the more the users use the Internet, the more the possibilities that they will become dependent on the Internet. Frequency of Internet use and time spent per day were positively correlated with privacy and self-defense. It suggests that higher frequency of Internet use and time spent online per day can cause behavioral problems and make people defensive, annoying and even aggressive. This is consistent with many past studies which found a correlation between the amount of time spent online and addictive behaviors suggesting that Internet usage is an important indicator of Internet addiction $[10,21,68,12]$. However, no significant correlation was found between different aspects of Internet use and life satisfaction and between different aspects of Internet use and life engagement. This was unexpected. The present study cannot explain these results.

This study has some limitations. First, the study was conducted with a moderate number of participants $(n=210)$. Second, the sample was chosen conveniently only from the University of Dhaka. So, the findings cannot be generalized to the other Internet user groups. Third, this study focused on the impact of Internet addiction on life satisfaction and life engagement without addressing the possibility that other variables might also influence all these two variables. Finally, the questionnaires were self-reported. It was therefore possible that some participants might not give their accurate response about their Internet addictions due to 
restricted social norms, even though this study was anonymous. In future, a similar survey can be conducted with a large number of randomly selected participants and including other potential variables (e.g., academic performance, family bonding, interpersonal relationship, parenting style). The future study can give more reliable information if some measures are taken to control or minimize the rate of false responses, especially to the personal questions (e.g., about Internet use).

\section{Conclusions and Suggestions}

Despite the above limitations the findings of the present study advance our understanding of the nature of Internet addiction and its impacts on life satisfaction and life engagement. The demonstration that Internet addiction has negative impacts on life satisfaction and life engagement will raise social awareness among the people in Bangladesh. From the broadcast of different media (e.g., newspapers, T.V., Internet blogs) we understand that youngsters of the country are vulnerable to a variety of social networks including Facebook, Twitter, Skype, hi5 etc. The findings of the present study are in line with those broadcasts. These findings can, therefore, be used to design fruitful suggestions for the sufferers to help them make proper use of the Internet. Finally, the findings can help us to design Internet management strategies and aid the policy makers and administrators in prevention, diagnosis and treatment of Internet addiction. For example, policy makers and administrators can take appropriate measures to train the counselors, set up counseling centers and offer treatment at counseling centers, clinics, and hospitals. As many health related problems are associated with Internet addiction, therapists and counselor should give attention and be prepared to deal with this problem. People who are already addicted may take help from psychologists or counselors. To help clients maintain abstain from problematic Internet applications, recovery interventions should apply structured, measurable, and systematic techniques. Cognitive-Behavioral Therapy (CBT) has been found to be the most effective approach with Internet-addicted clients [19]. Time to time monitor of Internet use is needed before the situation becomes uncontrollable. Internet addicts should be trained to develop time management and control on their use. Also, friends, family members or other relatives who are spending much more time on Internet, giving more preferences than real world important things should be encouraged to take advice from experts without any delay. So, parents, society as well as government should initiate some mental health campaign to promote the limited and proper use of Internet. Internet can be used as a media to promote productive work habits. Additionally, seminars, conferences and other activities could be organized to highlight the negative consequences of problematic Internet use. This kind of measures would make addicted people engage in their real life more easily, instead of creating a fantasized cyber world. At last, it can be suggested that people should monitor their own activity in using Internet.
This will help the youngsters not to use Internet in a destructive way. All this together will help maintain good mental health among people, particularly among the vulnerable student population of the country. Thus, we can conclude that the present findings have implications for theory, research and practice.

\section{Acknowledgements}

This piece of research was financially supported by the Ministry of Science and Technology, Government of Bangladesh.

\section{REFERENCES}

[1] Shek, T.L., Sun, C.F., \& Lu Yu. Internet addiction. Neuroscience in the $21^{\text {st }}$ century. Biomedical and Life sciences. Springer, 2013.

[2] Griffiths, M. Does internet and computer "addiction" exist? Some case study evidence. CyberPsychology and Behavior, 3 , 211-218, 2000.

[3] Yalın, H.I, Karataş, S., \& Karabulut, C.B. Internet addicted children and advices for teachers. World Conference on Educational Technology Researches (WCETR-2011), Near East University, Kyrenia-North Cyprus, 2011.

[4] Griffiths, M. Internet addiction: Fact or fiction? The Psychologist, 12(5), 246-250, 1999.

[5] Kandell, J.J. Internet addiction on campus: The vulnerability of college students. Cyberpsychology and Behavior, 1(1), 11-17, 1998 .

[6] Wang, W. Internet dependency and psychosocial maturity among college students. International Journal of Human-Computer Studies, 55(6), 919-938, 2001.

[7] Young, K.S. Internet addiction: The emergence of a new clinical disorder. CyberPsychology and Behaviour, 1, 237-244, 1996

[8] Young, K.S. \& Rogers, R. The relationship between depression and Internet addiction. CyberPsychology and Behavior, 1, 25-28, 1997.

[9] Yen, J., Ko, C., Yen, C., Wu, H., \& Yang, M. The comorbid psychiatric symptoms of internet addiction: Attention deficit and hyperactivity disorder (ADHD), depression, social phobia, and hostility. Journal of Adolescent Health, 41, 93-98, 2007.

[10] Chou, C., \& Hsiao, M.C. Internet addiction, usage, and gratifications the Taiwan's college students' case. Computers and Education, 35, 65-80, 2000.

[11] Young, K.S. Caught in the Net. New York, NY:John Wiley \& Sons, Inc, 1998.

[12] Morahan-Martin, J. \& Schumacher, P. Incidence and correlates of pathological internet use among college students. Computers in Human Behavior, 16, 13-29, 2000. 
[13] Scherer, K. College life on-line: healthy and unhealthy internet use. Journal of College Student Development, 38, 655-665, 1997.

[14] Tsai, C., \& Lin, S.S. Internet addiction of adolescents in Taiwan: An interview study. CyberPsychology and Behaviour, 6(6), 649-652, 2003.

[15] Beard, K.W. Internet addiction: current status and implications for employees. Journal of Employment Counselling, 39, 2-11, 2002.

[16] Weinstein, A., \& Lejoyeux, M. Internet addiction or excessive internet use. American Journal of Drug and Alcohol Abuse, 36(5), 277-83, 2010.

[17] Young, K.S. Internet Addiction FAQs. Retrieved fromhttp://www.healthy-place.com/ addictions/center-for-internet-addiction-recovery/internet-ad diction-faqs/menu-id-54/, 2009.

[18] Greenfield, D.N. Virtual addiction. Oakland, CA: New Harbinger Publications, Inc, 1999.

[19] Davis, R.A. A cognitive-behavioral model of pathological Internet use. Computers in Human Behavior, 17(2), 187-195, 2001.

[20] Caplan, S.E.A social skill account of problematic Internet use. Journal of Communication, 55, 721-736, 2005.

[21] LaRose, R., Lin, C.A. \& Eastin M.S. Unregulated Internet usage: addiction, habit, or deficient self-regulation? Media Psychology, 5, 225-53, 2003.

[22] Serin, B.N. An examination of predictor variables for problematic internet use. The Turkish Online Journal of Educational Technology, 10(3), 54-62, 2011.

[23] Yellowlees, P. \& Marks, S. Problematic Internet use or Internet addiction? Computers in Human Behavior, 23(3), 1447-1453, 2007.

[24] Grohol, J. Internet addiction guide. available at: http://psychcentral.com/netaddiction/, 1999.

[25] Özcan, N.K. \& Buzlu, S. Problematic use of the Internet is a tool to help determine the scale of cognitive status on the Internet, the reliability and validity of the university students. Journal of Addiction, 6(1), 19-26, 2005.

[26] Beard, K.W. Internet addiction: A review of current assessment techniques and potential assessment questions. CyberPsychology \& Behavior, 8(1), 7- 14, 2005.

[27] Serin, O. The effects of the computer-based instruction on the achievement and problem solving skills of the science and technology students. TOJET: The Turkish Online Journal of Educational Technology,10(1), 183-201, 2011.

[28] Cummins, R.A., \& Nistico, H. Maintaining life satisfaction: The role of positive cognitive bias. Journal of Happiness Studies, 3, 37-69, 2002.

[29] Shin, D.C., \&Johnson, D.M. Avowed happiness as an overall assessment of the quality of life. Social Indicators Research, $5,475-492,1978$.

[30] Diener, E. Subjective well-being. Psychological Bulletin, 95(3), 542-575, 1984.

[31] Andrews, F.M., \& Withey, S.B. Social indicators of well-being: America's perception of life quality. New York, NY: Plenum, 1976.

[32] Leung, L. Effects of internet connectedness and information literacy on quality of life. Springer Science Business Media B. $V, 2009$.

[33] Bozoglan, B., Demirer, V., \&Sahin, I. Loneliness, self-esteem, and life satisfaction as predictors of Internet addiction: a cross-sectional study among Turkish university students. Scandinavian Journal of Psychology, 54(4), 313-319, 2013.

[34] Pratarelli, M.E., Browne, B.L., \& Johnson, K. The bits and bytes of computer/Internet addiction: A factor analytic approach. Behavior Resistance and Methods Instrumental Computation, 31(2), 305-314, 1999.

[35] Affonso, B. Is the internet affecting the social skills of our children? Retrieved fromhttp://www.sierrasource.com/cep612/Internet.html, 1999.

[36] Shapira, N.A., Goldsmith, T.D., Keck, P.E., Jr., Khosla, U. M., \& McElroy, S.L. Psychiatric features of individuals with problematic internet use. Journal of Affective Disorder, 57, 267-272, 2000.

[37] Weiser, E.B. The functions of Internet use and their social and psychological consequences. Cyberpsychology and Behavior, 4, 723-742, 2001.

[38] Gross, E.F., Juvonen, J., \& Gable, S.L. Internet use and wellbeing in adolescence. The Journal of Social Issues, 58, 75-90, 2002.

[39] Sanders, C.E., Field, T.M., Diego, M. \& Kaplan, M. The relationship of Internet to depression and social isolation among adolescents. Adolescence, 35(138), 237-242, 2000.

[40] Wastlund, E., Norlander, T., \& Archer, T. Internet blues revisited: Replication and extension of an Internet paradox study. Cyberpsychology and Behavior, 4, 385-391, 2001.

[41] Carver, C.S., \& Scheier, M.F. On the Self Regulation of Behavior. New York, NY: Cambridge University Press, 1998.

[42] Scheier, M.F., Wrosch, C., Baum, A., Cohen, S., Martire, L. M., Matthews, K.A., . . . Zdaniuk, B. The Life Engagement Test: Assessing purpose in life. Journal of Behavioral Medicine, 29, 291-298, 2006.

[43] Carver, C.S., \& Scheier, M.F. Attention and Self-regulation: A control-theory approach to human behavior. New York, NY: Springer Verlag, 1981.

[44] Carver, C.S., \& Scheier, M.F. Origins and functions of positive and negative affect: A control-process view. Psychological Review, 97, 19-35, 1990.

[45] Atkinson, J.W. An Introduction to Motivation. Princeton, NJ: Van Nostrand., 1964.

[46] Feather, N.T. (Ed.) Expectations and actions: Expectancyvalue models in Psychology. Hillsdale, NJ: Erlbaum, 1982.

[47] Shah, J., \& Higgins, E.T. Expectancy X value effects: Regulatory focus as determinant of magnitude and direction. Journal of Perspective Social Psychology, 73, 447-458, 1997.

[48] Vroom, V.H. Work and Motivation. New York, NY: Wiley, 1964. 
[49] Against Child Abuse. The impacts of Internet on junior secondary school students: A research report. Against Child Abuse, Hong Kong, 2004.

[50] Choi, C.W., Wu, K.T., Zah, K.K. \& Ying, C.W. The impacts of Internet on adolescents' family relationships and mental health: A research report. Hong Kong Family Welfare Society, 2005.

[51] Lazar, K.A. Current life engagement factors as a predictor of elder life satisfaction (Masters thesis). Wisconsin: University of Wisconsin - Stout, 2000.

[52] Karim, A.K.M.R., \& Nigar, N. The Internet Addiction Test: Assessing its psychometric properties in Bangladeshi culture. Asian Journal of Psychiatry, 10, 75-83, 2014.

[53] Internet World Stats, Internet World Stats: Usage and Population Statistics. Retrieved from http://internetworldstats.com/stats.html, 2014.

[54] BTRC. Telco News Internet Subscribers in Bangladesh. Retrieved from http://www.btrc.gov.bd/, 2014.

[55] Frangos, C.C, Frangos, C.C., \& Kiohos, A. Internet addiction among Greek university students: Demographic associations with the phenomenon, using the Greek version of Young's Internet addiction test. International Journal of Economic Sciences and Applied Research, 3(1), 49-74, 2010.

[56] Cheung, G.W., \& Rensvold, R.B. Evaluating goodness-of-fit indexes for testing measurement invariance. Structural Equation Modeling, 9(2), 233-255, 2002.

[57] Celik, S., Atak, H., \& Basal, A. Predictive role of personality traits on Internet addiction. Turkish Online Journal of Distance Education-TOJDE, 13(4), 2012.

[58] Ni, X., Yan, H., Chen, S., \& Liu, Z. Factors influencing internet addiction in a sample of freshmen university students in China. CyberPsychology and Behavior, 12(3), 327-330, 2009.

[59] Ko, C.H., Yen, J.Y., Liu, S.C., Huang, C.F., \& Yen, C.F. The associations between aggressive behaviors and Internet addiction and online activities in adolescents. Journal of Adolescent Health, 44(6), 598-605, 2009.

[60] Widyanto, L., Griffiths, M.D., \& Brunsden, V. A psychometric comparison of the Internet addiction test, the Internet-related problem scale and self-diagnosis. Cyber psychology, Behavior and Social Networking, 14(3), 141-149, 2011.

[61] Widyanto, L., \& McMurran, M. The psychometric properties of the internet Addiction Test. CyberPsychology and Behavior, 7(4), 443-450, 2004.

[62] Shahnaz, I., \& Karim, A.K.M.R., Life satisfaction as a determinant of life engagement. Bangladesh Psychological Studies, 24, 2014.

[63] Diener, E., Emmons, R A., Larsen, R.J., \& Griffin, S. The Satisfaction with Life Scale. Journal of Personality Assessment, 49, 71-75, 1985.

[64] Nalwa, K. \& Anand, A.P. Internet addiction in students: a cause of concern. CyberPsychological Behavior, 6(6), 653-656, 2003.

[65] Baruch, Y. The autistic society. Information and Management 2001, 38, 129-136, 2004.

[66] Engelberg, E., \& Sjöberg, L. Internet use, social skills, and adjustment. Cyberpsychology and Behavior, 7, 41-47, 2009.

[67] Davis, R.A., Flett, G.L., \& Besser, A. Validation of a new scale for measuring problematic Internet use: Implications for pre-employment screening. Cyberpsychology and Behavior, 5(4), 331-345, 2002.

[68] Leung, L. Net-generation attributes and seductive properties of the Internet as predictors of online activities and Internet addiction. Cyberpsychology and Behavior, 7(3), 333-348, 2004.

[69] Li, S.M., \& Chung, T.M. Internet function and Internet addictive behavior. Computers in Human Behavior, 22(6), 1067-1071, 2006.

[70] Anderson, S.E., \& Gansneder, B.M. Using electronic mail surveys and computer-monitored data for studying computer-mediated communication systems. Social Science Computer Review, 13, 53-85, 1995.

[71] Statistics Finland. Survey on ICT usage in households and by individuals. Available at

http://www.stat.fi/til/sutivi/2007/sutivi_2007_2007-09-28_ti e 001 en. html, 2007. 